\title{
Precipitins and specific IgG antibody to Aspergillus fumigatus in a chest unit population
}

\author{
J A Faux, D J Shale, D J Lane
}

\begin{abstract}
Background The enzyme linked immunosorbent assay (ELISA) for detecting IgG antibodies to Aspergillus fumigatus is more sensitive than the measurement of Aspergillus precipitins. The relation of the results from both techniques to the clinical pattern of disease in a large unselected group of patients from a large referral centre is unknown.
\end{abstract}

Methods The clinical relation of precipitins to Aspergillus fumigatus to clinical disease was determined retrospectively in 98 patients attending a primary referral centre. Precipitin results were compared with the specific IgG antibody to $A$ fumigatus in 88 of the sera. Precipitins were determined by the agar gel double diffusion test and specific IgG antibody to $A$ fumigatus by a quantitative ELISA.

Results Precipitins were detected in the unconcentrated serum of 51 patients. Thirty nine of these had a mycetoma or allergic bronchopulmonary aspergillosis, 34 having specific IgG antibody to $A$ fumigatus more than the control range. Forty seven patients had precipitins only after threefold concentration of serum or to only one of the four $A$ fumigatus antigen extracts. Most of these had specific IgG in or near the control range. Thirty of these had $A$ fumigatus skin test negative asthma or bronchiectasis, in which aspergillus was probably not pathogenic. There was a close relation between the level of antibody detected by the ELISA and the number of precipitin lines.

Conclusions This study reaffirmed the supportive role of aspergillus precipitins in the diagnosis of pulmonary aspergillosis. No additional benefit in the routine use of the ELISA was seen. It also showed that care should be taken in interpreting positive precipitin results from concentrated serum and that using several rather than one $A$ fumigatus antigen extract is helpful for identifying allergic aspergillosis.

Aspergillus fumigatus is associated with mycetoma and allergic bronchopulmonary aspergillosis, the major non-invasive forms of pulmonary aspergillosis. $^{12}$ Precipitating antibody to $A$ fumigatus may be detected in serum in both disorders. ${ }^{3-5}$

Allergic bronchopulmonary aspergillosis, the most common cause of pulmonary eosinophilia, may cause irreversible fibrosis..$^{6-8} \mathrm{Diag}$ nosis is made on clinical and radiological criteria and supported by the finding of immediate skin reactivity, circulating specific IgE antibody to $A$ fumigatus, and precipitin lines on agar gel double diffusion in unconcentrated or concentrated serum. ${ }^{46}$ In these disorders precipitin results are useful and their interpretation straightforward. In routine practice, however, a precipitin test may be requested because of a suspicion of $A$ fumigatus involvement (as in difficult asthma), a positive skinprick test response to $A$ fumigatus, suspicious radiological appearances, or peripheral blood eosinophilia. It is in these circumstances that precipitin results with varying degrees of positivity occur, which prove difficult to interpret in the context of the supposed or eventual diagnosis.

The agar gel double diffusion method is the standard method for detecting Aspergillus precipitins, but it is a qualitative test of low sensitivity. Enzyme linked immunosorbent assay (ELISA) methods for detecting specific IgG antibodies to $A$ fumigatus have greater sensitivity. ${ }^{9-15}$ Many comparisons have been made between ELISA and agar gel double diffusion tests, but these have usually been limited to small numbers of highly selected patients. None has compared the clinical value of the two methods in routine practice.

We undertook this study to determine the meaning of a positive result in the precipitin test, to compare the agar gel double diffusion and ELISA methods in a primary referral population, and to evaluate the ELISA as a routine method for detecting IgG antibody to A fumigatus.

\section{Methods}

PATIENTS

Precipitins to $A$ fumigatus were detected in serum samples from 98 patients who attended a primary referral centre during seven years. The first positive serum precipitin sample was used in this study. On the basis of the precipitin results the following four groups were defined: group 1-patients with three or more precipitin lines in unconcentrated serum; group 2-patients with one or two precipitin lines in unconcentrated serum; group 3-patients with precipitins detectable 
only after threefold concentration of serum; group 4-patients with precipitins to only one or two of the four antigen extracts tested even after threefold concentration of serum and not to the same extract.

A group of 18 randomly selected precipitin negative patients attending the chest clinic served as controls for the ELISA data.

Case notes were reviewed to determine the diagnosis and collate results of clinic investigations. In particular, we recorded blood eosinophilia $\left(>0.5 \times 10^{9} / 1\right)$; positive skinprick test responses to $A$ fumigatus and other common allergens; $A$ fumigatus specific IgE (radioallergosorbent test (RAST), Phadenzym Pharmacia), sputum production, positive cultures, or microscopic appearances characteristic of $A$ fumigatus and lung function tests (either forced expiratory volume in one second $\left(\mathrm{FEV}_{1}\right)$, forced vital capacity (FVC), or peak expiratory flow (PEF). Chest radiographs were reviewed and subjects allocated to clinical groups by DJS without knowledge of their precipitin grouping. Mycetoma was diagnosed from the characteristic radiological appearances, consisting of the presence of a radio-opaque mass in a lung cavity with an air crescent. Allergic bronchopulmonary aspergillosis was diagnosed in accordance with accepted criteria: chest radiographic abnormalities, immediate cutaneous reactivity to Aspergillus, increased total and specific IgE antibodies to Aspergillus, peripheral blood eosinophilia, asthma, and proximal bronchiec$\operatorname{tasis}^{45}$ (though bronchography had not been performed on all patients). Bronchiectasis, not associated with allergic bronchopulmonary aspergillosis, was diagnosed from a history of chronic (over three years) purulent sputum production, bronchographs showing distal bronchiectasis, and an absence of immediate skin reactivity to $A$ fumigatus. Asthma was defined on the basis of a history of reversible symptoms of wheeze, chest tightness, and dyspnoea with a documented $15 \%$ reversibility of airflow obstruction $\left(\mathrm{FEV}_{1}\right.$ or PEF) in response to inhaled salbutamol $(200 \mu \mathrm{g})$.

AGAR GEL DOUBLE DIFFUSION

Each serum sample was tested against four extracts of $A$ fumigatus, two from Bencard, one from the Mycology Reference Laboratory, and one produced from a local strain.

Table 1 Distribution of diagnoses in the four precipitin groups (number of samples available for the enzyme linked immunosorbent assay in each group in parentheses)

\begin{tabular}{llllll}
\hline & \multicolumn{6}{l}{ Precipitin group } \\
\cline { 2 - 6 } Diagnosis & 1 & 2 & 3 & 4 & Total \\
\hline Mycetoma & $11(11)$ & - & - & - & $11(11)$ \\
ABPA & $12(12)$ & $16(15)$ & $7(7)$ & $1(0)$ & $36(34)$ \\
Asthma skin test negative & - & $4(3)$ & $8(7)$ & $9(7)$ & $21(17)$ \\
Bronchiectasis & - & $2(1)$ & $5(5)$ & $8(7)$ & $15(13)$ \\
Other diagnoses & - & $6(6)$ & $5(3)$ & $4(4)$ & $15(13)$ \\
Total & 23 & 28 & 25 & 22 & $98(88)$ \\
\hline
\end{tabular}

ABPA—allergic bronchopulmonary aspergillosis.
The local extract was produced from surface culture on a dialysable medium at $37^{\circ} \mathrm{C}$ for four to five weeks. ${ }^{1}$ The mycelial matt was homogenised in the culture filtrate, frozen, thawed, and sedimented at $3000 \mathrm{rev} / \mathrm{min}$. The supernatant was filtered through a membrane filter $(0.45 \mu \mathrm{m})$, dialysed against running tap water and then against two changes of distilled water at $4^{\circ} \mathrm{C}$, freeze dried, and used at a concentration of $20 \mathrm{mg} / \mathrm{ml}$. Four extracts were used to include as many antigens of $A$ fumigatus as possible. After staining and drying, precipitin lines were counted (JAF) and recorded as the greatest number reacting to any extract. ${ }^{16}$ Serum samples were stored at $4^{\circ} \mathrm{C}$ with $0.1 \%$ sodium azide until assayed in the ELISA.

ELISA FOR IgG ANTIBODIES TO A FUMIGATUS An antibody capture assay was developed with an antigen extract from a locally isolated strain of $A$ fumigatus. The intra-assay and interassay coefficient of variation for the local strain was below $10 \%$. Results were expressed in terms of a specific binding index for each specimen with reference to a highly positive laboratory standard. ${ }^{13}$ This index was derived as follows:

$$
\frac{O D_{x}-O D_{l c}}{O D_{h c}-O D_{l c}} \times 100,
$$

where $\mathrm{OD}_{x}$ is the optical density of unknown serum, $\mathrm{OD}_{\mathrm{hc}}$ the mean optical density of highly positive serum, and $O D_{l c}$ the mean optical density of negative control serum.

\section{STATISTICAL METHODS}

Data were analysed by precipitin group and clinical group. The ELISA data were skewed, so the significance of differences between groups was assessed by the Mann-Whitney $U$ test. Exact critical values and $p$ values below 0.05 were accepted as significant and are quoted as such to simplify presentation. Results are expressed as medians with corrected $25 \%$ and $75 \%$ interquartile ranges (Qlc and $\mathrm{Q} 3 \mathrm{c}$ ).

\section{Results}

The most frequent diagnosis was asthma, which occurred in 57 of the 98 patients and was evenly distributed between the four precipitin groups (table 1). The proportion of patients with allergic bronchopulmonary aspergillosis, all of whom had asthma, was much less in group 4-1/10 versus $12 / 12,16 / 20$, and $8 / 15$ in groups 1,2 , and 3 respectively. Mycetoma was found in 11 patients and bronchiectasis in 15 patients. Of the remaining 15 subjects, seven had chronic irreversible airways obstruction without features of asthma; four had pulmonary fibrosis related to tuberculosis, sarcoidosis, and ankylosing spondylitis; and the remainder may have been colonised by aspergillus because of altered lung clearance mechanisms due to carcinoma (2) and severe pneumonia leading to chronic necrotising pulmonary aspergillosis (2). 
Table 2 Specific binding indices for each precipitin group and the control group

\begin{tabular}{llll}
\hline & & \multicolumn{2}{c}{ Specific binding index } \\
\cline { 3 - 4 } & $\begin{array}{l}\text { Precipitin } \\
\text { lines }\end{array}$ & Median & $\begin{array}{l}\text { Interquartile } \\
\text { range }\end{array}$ \\
\hline Group 1 & $>2$ & $81^{\star}$ & $75-103$ \\
Group 2 & $1-2$ & $28^{\star}$ & $25 \cdot 8-34 \cdot 7$ \\
Group 3 & Concentrated & & $16 \cdot 6-25 \cdot 7$ \\
& serum $\dagger$ & $19 \ddagger$ & $16-3-6 \cdot 8$ \\
Group 4 & Variable & $4 \ddagger$ & $0-4 \cdot 5$ \\
Controls & Zero & 3 & \\
\hline
\end{tabular}

* $p<0.05$ between these groups.

tDetectable only after threefold concentration of serum. $\ddagger \mathrm{p}<0.05$ between these groups.

\section{CLINICAL ASSESSMENTS}

Apart from sputum culture and microscopy for A fumigatus, $83 \%$ of patients had skin tests, $96 \%$ tests for blood eosinophils, and $71 \%$ tests for sputum eosinophils. All asthmatic patients with a negative skin prick test response to $A$ fumigatus had specific IgE to $A$ fumigatus determined and one third had a positive result. A positive skin test response or specific IgE antibody to $A$ fumigatus was recorded in all the patients with allergic bronchopulmonary aspergillosis and in a quarter of the patients with a myectoma, but in no other patients. Three of the aspergillus skin test negative patients with asthma had specific IgE antibody to one or more common allergens and blood eosinophilia of similar magnitude to that seen in the patients with allergic bronchopulmonary aspergillosis. Sputum culture for $\boldsymbol{A}$ fumigatus was performed for only 31 subjects in groups 1 and 2 and 19 in groups 3 and 4 . Positive cultures occurred twice as often in groups 1 and 2 as in groups 3 and 4.

\section{RELATION BETWEEN PRECIPITIN AND ELISA} RESULTS

The median specific binding index was greatest for group 1 and lowest in group 4. There were

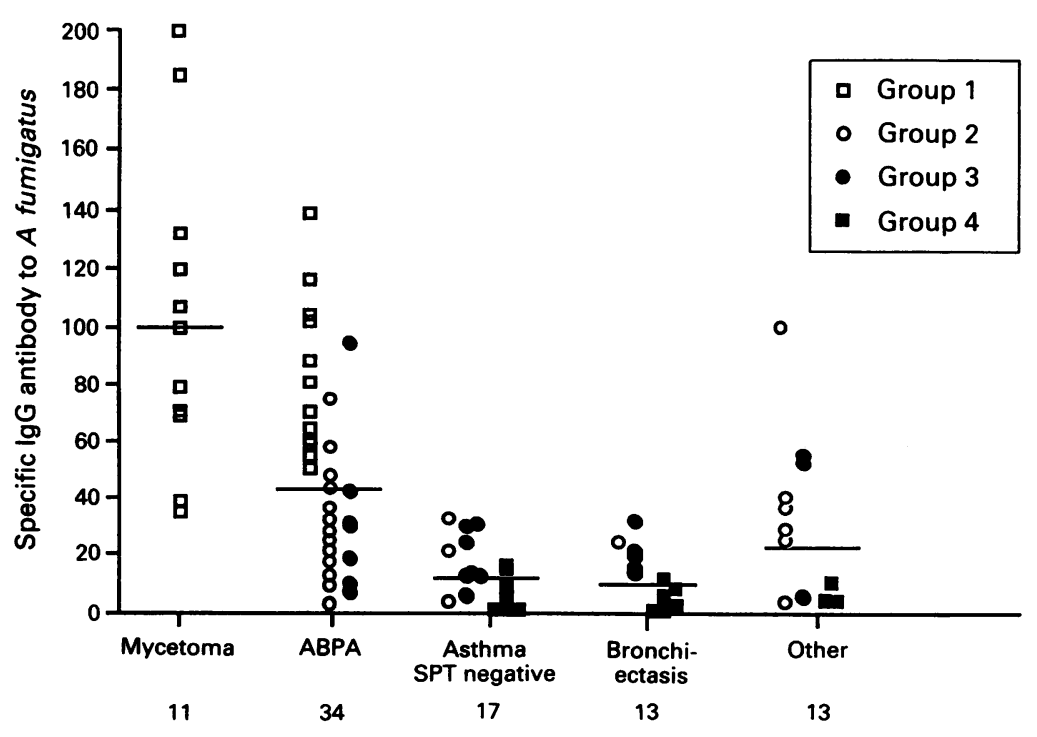

Comparison of specific IgG antibody to Aspergillus fumigatus (specific binding index) and precipitins (groups 1-4) for the major diagnostic groups. ABPA-allergic bronchopulmonary aspergillosis; SPT-skinprick test negative.
Table 3 Specific binding indices for the major diagnostic groups and the precipitin negative control serum samples

\begin{tabular}{|c|c|c|c|}
\hline \multirow[b]{2}{*}{ Diagnosis } & \multicolumn{2}{|c|}{ Specific binding index } & \multirow[b]{2}{*}{$n \dagger$} \\
\hline & Median & $\begin{array}{l}\text { Interquartile } \\
\text { range }\end{array}$ & \\
\hline Mycetoma & $100 \star$ & $82 \cdot 5-140 \cdot 3$ & $11 / 11$ \\
\hline ABPA & $43 \cdot 5^{\star}$ & $36 \cdot 1-59 \cdot 6$ & $34 / 36$ \\
\hline \multicolumn{4}{|l|}{ Asthma aspergillus } \\
\hline negative & 12 & $3 \cdot 6-17 \cdot 8$ & $17 / 21$ \\
\hline Bronchiectasis & 10 & $6 \cdot 1-15 \cdot 4$ & $13 / 15$ \\
\hline Others & 25 & 4-39 & $13 / 15$ \\
\hline Controls & 3 & $0-4.5$ & 18 \\
\hline
\end{tabular}

${ }^{\star} \mathrm{p}<0.05$ in the comparison with all following groups.

$\dagger$ Number of serum samples available for the enzyme linked immunosorbent assay.

ABPA - allergic bronchopulmonary aspergillosis.

significant differences between groups 1 and 2 and groups 3 and 4, but not between groups 2 and 3 or between group 4 and precipitin negative controls. Groups 1, 2, and 3 had significantly greater specific binding index values than group 4 and controls, who had a range of 1-18 (table 2). The specific binding index and precipitin line results of groups 1 and 2 (positive in unconcentrated serum) were significantly related $(r=0.08, p<0.001$, $\mathrm{df}=45$ ).

\section{CLINICAL GROUPS}

Mycetoma

All patients with a mycetoma had more than two precipitin lines in unconcentrated serum. The specific binding index values were higher than those found in the other clinical groups (p < 0.05; table 3$)$.

\section{Allergic bronchopulmonary aspergillosis}

Most patients with allergic bronchopulmonary aspergillosis $(28 / 36)$ had precipitins in unconcentrated serum (groups 1 and 2); the remainder were in group 3, apart from one patient in group 4. A wide range of antibody levels was seen by the ELISA. The specific binding index values were significantly lower than those seen in the patients with mycetoma (though individual results overlapped), but the values were significantly greater than those seen in the other clinical groups (figure, table 3). The subjects with allergic bronchopulmonary aspergillosis in group 3 had significantly lower values than those in groups 1 and 2 (median 30, Q1c 18.3, Q3c 34.8, $\mathrm{n}=7$, versus median 50, Q1c 39.8, Q3c 61.3, $\mathrm{n}=27$; $\mathrm{p}=0.05)$. The patients in group 3 were also separated significantly from patients with no precipitins and from patients with skin test negative asthma, though individual results overlapped. Nine patients with allergic bronchopulmonary aspergillosis had no radiographic evidence of disease at the time of assessment. ${ }^{17-19}$ Their median specific binding index was less than that of the remainder of the group (those with no radiological evidence: median 24, Q1c 23.8, Q3c 40.3, $n=9$; those with radiological evidence: median 48, Q1c 37.5, Q3c 62.5, $\mathrm{n}=23 ; \mathrm{p}<0.05$ ).

\section{Aspergillus skin test negative asthma}

Of the 21 patients with aspergillus skin test 
negative asthma, only three had positive skinprick test responses to other antigens, though 13 had a recorded absolute peripheral blood eosinophilia. Four patients were in group 2 , eight were in group 3, and nine were in group 4. The ELISA showed a low level of specific antibody to $A$ fumigatus in the serum of 17 of these patients. The specific binding index values in this group did not differ from those of the controls and the patients with bronchiectasis and were lower than those of the group with allergic bronchopulmonary aspergillosis $(\mathrm{p}<0.05$; table 3$)$.

\section{Bronchiectasis}

All the patients with bronchiectasis had airways obstruction $\left(\mathrm{FEV}_{1} / \mathrm{FVC}\right.$ below $\left.70 \%\right)$ and a negative skinprick test response to $A$ fumigatus. Most were in precipitin groups 3 and 4. The ELISA results showed antibody levels that were insignificantly different from those of the patients with skin test negative asthma and the precipitin negative control group.

Other diagnoses

Patients in this group had negative skinprick test responses and no IgE antibody to $A$ fumigatus. Of the 15 patients, six had one or two precipitin lines and five had precipitins after concentration of the serum, but none was considered to have aspergillosis. The ELISA results showed moderate antibody levels, though the median specific binding index of 25 was less than that in the mycetoma group $(\mathrm{p}<0.05)$.

\section{Discussion}

This study reviewed the clinical significance of precipitins for positive $A$ fumigatus determined by the agar gel double diffusion test in patients attending a primary referral chest clinic and compared these findings with those obtained by an ELISA method.

Precipitin groups $1-4$ on the agar gel double diffusion test compared closely with the results of ELISA. More than $90 \%$ of individuals with precipitins in unconcentrated serum had a specific binding index significantly above control values. Previous comparisons between agar gel double diffusion and ELISA have been based on small numbers of subjects with well defined diseases by ELISA results. Separation between serum from control subjects, serum from non-atopic subjects, and serum with one or two precipitin lines has not always been possible. $^{9-12}$ In a comparison based on 758 serum samples collected from patients attending a chest clinic $81 \%$ (615) were negative by both agar-gel double diffusion and ELISA methods and, of the $127(19 \%)$ positive by ELISA, only 39 were positive by agar gel double diffusion. Only 46 serum samples were from patients with aspergillosis, however. ${ }^{20}$ It was concluded that the ELISA could detect antibodies against non-precipitating antigenic components of $A$ fumigatus in addition to the antibodies detected by agar gel double diffusion..$^{20}$ Using an optimised ELISA, ${ }^{13}$ we have found a clear relation between the results of the two methods. The ELISA also separated the different precipitin groups, although it did not completely distinguish the mycetoma and allergic bronchopulmonary aspergillosis groups from the non-aspergillosis groups.

In this study 43 of the 51 patients with precipitins in unconcentrated serum had a mycetoma or asthma and 28 of the 32 with asthma had allergic bronchopulmonary aspergillosis. Of the eight patients with neither myectoma nor asthma in groups 1 and 2, four died soon after assessment and the development of antibody to $A$ fumigatus was probably a terminal event related to impaired lung clearance mechanisms. Of the remainder, one had cystic fibrosis, one was repeatedly precipitin positive, and a further patient, with a specific binding index of 100 , had extrinsic allergic alveolitis, probably related to exposure to aspergillus while working in a stable.

The clinical relevance of precipitins detected only after threefold concentration of serum may be difficult to determine. In this study only a third of patients in group 3 had aspergillosis. In patients with allergic bronchopulmonary aspergillosis such results have always been considered to be positive. The proportion of precipitin positive patients with allergic bronchopulmonary aspergillosis increased from $60 \%$ to $84 \%$ when precipitins in concentrated serum were considered to represent a positive result. ${ }^{4}$ The group 3 patients with allergic bronchopulmonary aspergillosis had significantly greater amounts of specific IgG according to ELISA than did the precipitin negative controls, suggesting that their precipitin results are clinically relevant. Among the patients with allergic bronchopulmonary aspergillosis, those in group 3 had specific binding index values significantly below those in groups 1 and 2, though the separation of most of the seven patients in group 3 from the precipitin negative controls and the asthmatic patients with a negative skin test response to $A$ fumigatus suggests that precipitin results in concentrated serum should be considered to be positive when other criteria of allergic bronchopulmonary aspergillosis are met. The ELISA suggests that care is needed in interpreting the group 4 precipitin results. If precipitin lines are obtained, especially if weak and in response to only one extract in a patient without evidence of myectoma or allergic bronchopulmonary aspergillosis, further samples may be helpful.

Patients with skin test negative asthma had a lower median specific binding index than the patients with allergic bronchopulmonary aspergillosis and, although two thirds had blood eosinophilia, none had radiological changes of bronchopulmonary aspergillosis. This supports the suggestion that specific IgE in addition to specific IgG is needed to produce the chronic inflammatory changes seen in the bronchi with allergic bronchopulmonary aspergillosis. ${ }^{67}$ The patients with bronchiectasis had been reported to have precipitins, but none had a positive skinprick test response and the ELISA confirmed low concentrations of specific IgG in this group. Poor tracheobronchial clearance mechanisms may have made 
these patients more exposed to aspergillus antigen than are normal subjects, leading to the production of precipitating antibody.

The ELISA had no major advantages over the routine determination of precipitins in the diagnosis of non-invasive pulmonary aspergillosis, unless the use of expanded diagnostic criteria for allergic bronchopulmonary aspergillosis are adopted. ${ }^{56} \mathrm{~A}$ compatible history and radiological appearances and a positive response to the $A$ fumigatus skinprick test or specific IgE in patients with precipitins in unconcentrated or threefold concentrated serum may be taken to indicate the presence of allergic bronchopulmonary aspergillosis. Weak precipitin reactions were not a feature of mycetoma and their presence in patients not meeting other criteria of allergic bronchopulmonary aspergillosis rules out any important degree of pulmonary aspergillosis. The ELISA used in a quantitative form allows within and between patient comparisons, ${ }^{13}$ whereas the agar gel double diffusion test is semiquantitative, subjective, and too insensitive for monitoring the progress of allergic bronchopulmonary aspergillosis. ${ }^{49}$ The use of the ELISA may have a further clinical advantage in that the presumed pre-injury phase of allergic bronchopulmonary aspergillosis may be diagnosed by using ELISAs for $A$ fumigatus specific IgG and IgE antibody. This might be of value as allergic bronchopulmonary aspergillosis may not be diagnosed according to current standard criteria until appreciable loss of lung function has occurred, ${ }^{467}$ though there is no evidence that treatment at this stage reduces lung destruction.

We are grateful to Janssen Pharmaceutical Ltd, UK, for financial support and to Miss $\mathrm{H}$ Alexander for preparation of the manuscript.

1 Austwick PKC. Fungi and actinomycetes. In: Scadding JG, Cumming G, and Thurlbeck WM, eds. Scientific foundaion of respiratory medicine. London: Heinemann, 1981 396-413.

2 Hinson KFW, Moon AJ, Plummer NS. Bronchopulmonary aspergillosis. A review and a report of eight new cases. Thorax 1953;7:317-33.
3 Longbottom JL, Pepys J. Pulmonary aspergillosis; diagnostic and immunological significance of antigens and substance in Aspergillus fumigatus. $J$ Pathol Bacterio 1964;88:141-51.

4 Malo JL, Longbottom JL, Mitchell J, Hawkins R, Pepys J. Studies in chronic allergic bronchopulmonary aspergillosis-3. immunological findings. Thorax 1977;32. 269-74.

5 Rosenberg M, Patterson R, Mintzer R, Cooper BJ, Roberts $M$, Harris KE. Clinical and immunological criteria for the $M$, Harris $\mathrm{KE}$. Clinical and immunological criteria for the Intern Med 1977;86:405-14.

6 Patterson R, Greenberger PA, Hawing JM, Liota JL Roberts $M$. Allergic bronchopulmonary aspergillosis natural history and classification of early disease by serologic and roengenographic studies. Arch Intern Med 1986;146:916-8.

7 Greenberger PA, Patterson R. Allergic bronchopulmonar aspergillosis and the evaluation of the patient with asthma. $J$ Allergy Clin Immunol 1988;81:646-50.

8 Chapman BJ, Capewell S, Gibson R, Greening AP, Crompton GK. Pulmonary eosinophilia with and without allergic bronchopulmonary aspergillosis. Thorax 1989;44:919-24.

9 Sepulveda R, Longbottom JL, Pepys J. Enzyme linked immunosorbent assay (ELISA) for IgG and IgE antibodies of protein and polysaccharide antigens to Aspergillus fumigatus. Clin Allergy 1979;9357-71.

10 Greenberger PA, Patterson R. Application of an enzymelinked immunosorbent assay (ELISA) in diagnosis of allergic bronchopulmonary aspergillosis. J Lab Clin Med allergic bronchop

11 Mishra SK, Falkenberg S, Masihi KN. Efficacy of enzymelinked immunosorbent assay in serodiagnosis of asper gillosis. J Clin Microbiol 1983;17:708-10.

12 Khan ZV, Richardson MD, Warnock DW. Evaluation of a rapid enzyme-linked immunosorbent assay for IgG antibodies to Aspergillus fumigatus in the serological diagnosis of allergic aspergillosis. Int Arch Allergy Appl Immunol 1983;72:205-11.

13 Shale DJ, Faux JA. The evaluation of a quantitative enzyme linked immunosorbent assay (EI ISA) for anti $A$ fumigatus IgG. J Immunol Methods 1985;77:197-205.

14 Kauffman HF, van der Heide S, Beaumont F, Blok $H$, de Vries K. Class specific antibody determination against Aspergillus fumigatus by means of the enzyme-linked Aspergillus fumigatus by means of the enzyme-linked immunosorbent

15 Brummond W, Resnick A, Fink JN, Kurup VP. Aspergillus fumigatus-specific antibodies in allergic bronchopulmonary aspergillosis and aspergilloma: evidence of a polyclonal antibody response. J Clin Microbiol 1987;25:5-9.

16 Faux JA, Stanley VC, Buckley JR, Partridge BM. A comparison of different extracts of Candida albicans in agar gel double diffusion techniques. J Immunol Methods 1975;6:235-47.

17 McCarthy DS, Simon G, Hargreave FE. The radiological appearances in alleroic bronchopulmonary aspergillosis. Clin Radiol 1970;21:266-75.

18 Malo JL, Pepys J, Simon G. Studies in chronic allergic bronchopulmonary aspergillosis. II Radiological findings. Thonchopulmonary asper.

19 Mintzer RA Rogers LF, Kruglik GD, et al. The spectrum of radiographic findings in allergic bronchopulmonary asperradiographic findings in allergic bro

20 Kauffman HF, Beaumont F, Meurs H, van der Heide S, de Vries K. Comparision of antibody measurements agains Aspergillus fumigatus by means of double diffusion and enzyme linked immunosorbent assay (ELISA). J Allergy Clin Immunol 1983;72:255-61. 